\title{
Implikasi Pedagogi Paulo Freire dan Antonia Harder Terhadap Tindak Pidana Perdagangan Manusia di Nusa Tenggara Timur
}

\author{
Jear Nenohai \\ Calon Vikaris di Gereja Masehi Injili di Timor \\ nenohai46@gmail.com \\ D01: https://doi.org/10.34307/b.v4i1.211
}

\begin{abstract}
Current research on human trafficking in the Christian Evangelical Church in Timor (GMIT) does not currently involve an educational approach to analyze the problem. So, the aim of this article is to contribute ideas about the pattern of contextual education for GMIT in countering human trafficking cases in East Nusa Tenggara. This study is based on a literature study comparing the critical pedagogy of Paulo Freire and Antonia Harder. After that, the authors uses this pedagogy to analyze the praxis of the mission of the Christian Evangelical Church in Timor and the contextual education practices of an alternative school named Lakoat.Kujawas. Through the mission and education dialogue, the authors see that the resistance base of GMIT has not involved culture and nature as a basis for resistance. Through the critical pedagogical analysis of Freire and Antonia Harder, the author shows the relevance of Lakoat.Kujawas's liberation pedagogy and contextual education model for the resistance process undertaken by GMIT. Finally, this research is limited to the exploration of critical pedagogy for cases of human trafficking and not involve further politic of education, intercultural theological and practical studies on the pedagogy of liberation.
\end{abstract}

Keywords: human trafficking, Christian Evangelical Church in Timor, Freire, Harder, critical pedagogy

Abstrak: Penelitian mengenai perdagangan manusia di Gereja Masehi Injili di Timor (GMIT) saat ini belum melibatkan pendekatan pendidikan untuk menganalisis masalah tersebut. Jadi, tujuan dari artikel ini adalah untuk memberikan sumbangsih pemikiran mengenai pola pendidikan konstekstual bagi GMIT dalam melawan kasus perdagangan manusia di Nusa Tenggara Timur. Penelitian ini didasarkan pada studi literatur yang membandingkan pedagogi kritis dari Paulo Freire dan Antonia Harder. Setelah itu, penulis menggunakan pedagogi tersebut untuk menganalisis praksis misi perlawanan Gereja Masehi Injili di Timor dan praktik pendidikan kontekstual dari sekolah alternatif bernama lakoat.kujawas. Melalui dialog misi dan pendidikan tersebut, penulis melihat bahwa basis perlawanan GMIT belum melibatkan kebudayaan dan alam sebagai basis perlawanan. Melalui analisa pedagogi kritis ala Freire dan Antonia Harder, penulis menunjukan relevansi dari pedagogi pembebasan dan model pendidikan kontekstual Lakoat.Kujawas bagi proses perlawanan yang kerjakan oleh GMIT. Akhir kata, Penelitian ini terbatas pada eksplorasi pedagogi kritis untuk kasus-kasus perdagangan manusia dan belum melibatkan dimensi politik pendidikan, kajian teologis dan praktis lebih jauh tentang pedagogi pembebasan.

Kata kunci: perdagangan manusia, Gereja Masehi Injili di Timor, Freire, Harder, pedagogi kritis, lakoat.kujawas 


\section{Pendahuluan}

Tulisan ini berangkat dari hasil pembacaan penulis atas dua buah buku kajian teologi dan rumpun ilmu lainnya terkait tindak pidana perdagangan orang di Nusa Tenggara Timur (selanjutnya disingkat TPPO di NTT), yang cukup komperhensif, yakni "Menolak Diam: Gereja Melawan Perdagangan Orang terbitan BPK Gunung Mulia pada tahun 2018 dan "Tuhan Tak Berdagang: Perdagangan Orang, Trauma, dan Teologi di Nusa Tenggara Timur" terbitan BPK Gunung Mulia pada tahun 2020. Dalam pembacaan penulis, kedua buku tersebut belum memasukkan dimensi pendidikan Kristen sebagai sebuah pisau bedah untuk melawan kasus perdagangan manusia yang kini masih terus terjadi, padahal, dalam pengantar pada salah satu buku yang penulis sebutkan, Mery Kolimon, teolog sekaligus pejuang kemanusiaan perdagangan manusia di NTT, juga melihat kebutuhan itu. ${ }^{1 "}$ Dalam konteks seperti itu (perdagangan manusia), umat mesti dididik untuk mengatakan tidak pada kekerasan. Untuk itu, gereja perlu mengembangkan pendidikan kritis agar umat dan warga masyarakat mampu menolaknya sebagai sikap iman." ${ }^{2}$

Merespon pendapat Mery Kolimon, penulis sependapat bahwa perlu diadakannya program pendidikan kristen bagi GMIT untuk merespon isu perdagangan manusia. Mengapa harus pendidikan? Kajian pendidikan agama Kristen (PAK) dalam pengertian yang lebih mendalam adalah kajian yang menempatkan pokok iman sebagai kajian bagi kehidupan orang percaya secara keseluruhan sekaligus sebuah upaya untuk hidup dalam pemahaman iman akan Allah yang dibangun tersebut. Dalam pemahaman Jack Seymour, seorang ahli Pendidikan Agama Kristen dari tradisi metodis, PAK adalah pendekatan yang dapat membantu umat percaya "mengintegrasikan" iman Kristen dengan kehidupan keseharian. ${ }^{3}$ Dengan kata lain PAK memungkinkan sebuah pemahaman iman mendapat fungsi kontekstual dan aktualitasnya. Lebih lanjut, Daniel Schipani, seorang pemikir PAK yang banyak banyak bergelut dalam kiat persoalan Gereja dan Masyarakat, mengatakan bahwa Gereja bertanggungjawab dalam menyokong masyarakat yang bersentuhan langsung dalam persoalan sosial. Tulis Schipani, pendidikan Kristen jemaat mengupayakan kebangkitan manusia dalam terang pemerintahan Allah. ${ }^{4}$ Maka dari itu pendidikan Gereja tidak boleh menutup mata para persoalan masyarakat luas sebagai medan pelayanan Gereja. Dalam pendidikan yang bergerak dalam bidang sosial, Gereja mewartakan kasih dan keikutsertaan Allah.

\footnotetext{
${ }^{1}$ Mery Kolimon, "Misi Perlawanan Gereja," in Perdagangan Orang, Trauma, Dan Teologi Di Nusa Tenggara Timur, ed. Karen Campbell-Nelson (Jakarta: BPK Gunung Mulia, 2020), 245.

${ }^{2}$ Kolimon, "Misi Perlawanan Gereja."

3 Jack Seymour, "Pendekatan-Pendekatan Pendidikan Kristiani," in Memetakan Pendidikan Kristani: “Pendekatan-Pendekataan Menuju Pembelajaran Jemaat, ed. Jack Seymour (BPK Gunung Mulia, 2018), 183.

${ }^{4}$ Daniel Schipani, "Pendidikan Transformasi Sosial," in Memetakan Pendidikan Kristani: PendekatanPendekataan Menuju Pembelajaran Jemaat, ed. Jack Seymour (Jakarta: BPK Gunung Mulia, 2018), 186.
} 
Maka dari itu, tulisan ini dirancang untuk menjawab pendidikan kritis seperti apa yang diperlukan oleh warga GMIT dalam merespon kasus perdagangan manusia di Nusa Tenggara Timur? Dalam artikel ini, penulis membangun dasar pendidikan GMIT dalam menanggapi persoalan tindak pidana perdagangan manusia bagi warga GMIT yang mampu menyentuh aspek-aspek di luar percakapan Teologi. Lebih spesifik lagi, tulisan ini bertujuan memperkuat misi perlawanan yang ditandaskan oleh Mery Kolimon dan basis pendidikan kontekstual dan kemasyarakatan dari Lakoat.Kujawas, sebuah sekolah alam dan pendidikan alternatif di Mollo-Nusa Tenggara Timur, melalui paradigma pendidikan Paulo Freire dan pemikir sesudahnya yakni Antonia Harder. Penulis berpendapat bahwa melalui paradigma pendidikan kritis yang diperlukan bagi warga GMIT ialah pendidikan kristen yang aktif melibatkan kebudayaan dan penguatan ekonomi kemasyarakatan.

Demi membangun gagasan penulis terkait program pendidikan GMIT sebagai bagian dari misi perlawanan terhadapan TPPO di Nusa Tenggara Timur, penulis membangun alur tulisan ini sebagaimana berikut; pertama, penulis menjabarkan garis besar pemikiran refleksi kritis Paulo Freire dan Antonia Harder sebagai pola pemikiran yang akan penulis pakai. Kedua, penulis menganalisa implikasi perlawanan GMIT terhadap TPPO di NTT yang sedang berlangsung melalui konsep pendidikan kritis Freire dan Harder. Ketiga, penulis menganalisa proses pendidikan di Lakoat.Kujawas dan relevansinya bagi GMIT. Keempat, penulis membuat kesimpulan catatan refleksi yang penulis tawarkan dengan berangkat dari hasil konstruksi pedagogi kritis Freire dan Harder serta Lakoat.Kujawas.

\section{Metode Penelitian}

Dalam tulisan ini, penulis menganalisis respon warga GMIT dan aksi GMIT terhadap kasus perdagangan manusia di Nusa Tenggara Timur melalui pendekatan pendidikan Paulo Freire dan Antonia Harder. Oleh karena itu, artikel ini menggunakan pendekatan kualitatif dan dan wawancara. Pendekatan kualitatif (analisa kritis dan kajian pustaka) penulis gunakan terhadap literatur pendidikan Paulo Freire dan Antonia Harder terhadap kasus perdagangan manusia di Nusa Tenggara Timur. Maka dalam tulisan akan banyak ditemukan argumentasi dan deskripsi analitis penulis terhadap tindak pidana perdagangan orang di Nusa Tenggara Timur (TPPO di NTT). Lebih lanjut, setelah membangun dasar pendidikan untuk GMIT, penulis menggunakan menganalisa hasil wawancara dan liputan media terhadap model pendidikan di Lakoat.Kujawas sebagai salah satu contoh bangunan pendidikan yang bisa dijadikan contoh oleh GMIT dalam melawan tindak pidana perdagangan orang di Nusa Tenggara Timur (TPPO di NTT). Kedua hasil kuantitatif dan kualitatif kemudian penulis bangun dalam argumentasi yang kontruktif untuk menghasilkan kajian kritis model pendidikan kontekstual bagi GMIT dalam konteks perdagangan manusia. 


\section{Hasil dan Pembahasan}

\section{Pendidikan Kemanusiaan Paulo Freire}

Dari pengalaman perlawanan terhadap praktik pembodohan kepada kaum petani di Brasil pada masanya, cakupan model pembebasan dari pedagogi Freire memberikan pemahaman baru dalam membaca narasi kekerasan dalam berbagai ranah seperti ekonomi, politik, kebudayaan, dan terutama pendidikan. ${ }^{5}$ Secara garis besar, filsafat pendidikan Freire bertujuan untuk menciptakan kesadaran kritis agar manusia bisa hidup secara independen sekaligus politis. Pembebasan hanya terjadi apabila subjek atau masyarakat hidup dalam kesadaran kritis atau conscientizacao. ${ }^{6}$ Conscientizacao hadir sebagai perangkat untuk memastikan tindakan-reflektif subjek mampu mengubah struktur sosial-budaya yang menindas secara berkelanjutan. ${ }^{7}$

Conscientizacao memastikan masyarakat tertindas untuk hidup secara otonom dan kritis. Subjek yang kritis adalah subjek yang tidak lagi terkekang pada kesadaran mistis; kesadaran bahwa penindasan akan diselesaikan oleh intervensi supranatural. ${ }^{8}$ Conscientizacao juga menghubungkan diri manusia dengan dunia kehidupannya. Conscientizacao yang dirancang Paulo Freire bertugas untuk mendidik manusia hidup di dalam (in) dan bersama (with) dunia. Kemenyatuan manusia dengan dunianya ini disebut Freire sebagai bagian dari pendidikan hadap-masalah. Tulis Freire,

Pendidikan hadap masalah, manusia mengembangkan kemampuannya untuk memahami secara kritis cara mereka mengada dalam dunia dengan mana dan dalam mana mereka menemukan diri sendiri; mereka akan memandang dunia bukan sebagai realitas yang statis, tetapi sebagai realitas yang berada dalam proses, dalam gerak perubahan. ${ }^{9}$

Subjek yang kritis tidak hanya melahirkan kemandirian bertindak tetapi juga solidaritas kemanusiaan. ${ }^{10}$ Solidaritas kemanusiaan hadir sekaligus untuk menjadi landasan ontologis pengharapan agar perjuangan bisa menjadi perjuangan antar generasi alias tidak berhenti dan bersifat temporer. ${ }^{11}$ Maka dari itu, pendidikan kemanusiaan Freire selalu bersifat politis. ${ }^{12}$ Pendidikan, dalam hal ini, hadir sebagai sebuah aksi untuk membebaskan manusia dari alienasi penindasan dan menghadirkan kembali manusia sebagai agen kehidupan. Pendidikan dan kemanusiaan hadir sebagai perjuangan kaum tertindas demi pembebasan yang universal dan kekal. 2011).

${ }^{5}$ Denis Collins, Paulo Freire: Kehidupan, Karya, Dan Pemikirannya (Yogyakarta: Pustaka Pelajar,

${ }^{6}$ William. A. Smith, Conscientizacao: Tujuan Pendidikan Paulo Freire (Yogyakarta: Pustaka Pelajar, 2008).

7 Sastrapratedja Danuwinata, Filsafat Pendidikan Paulo Freire (Jakarta: Sekolah Tinggi FIlsafat Driyarkara, 1984).

${ }^{8}$ Paulo Freire, Pendidikan Kaum Tertindas (Jakarta: Pustaka LP3ES Indonesia, 2008).

${ }^{9}$ Ibid.

${ }^{10}$ Paulo Freire, Pedagogi Hati (Yogyakarta: Kanisius, 2001).

${ }^{11}$ Paulo Freire, Pedagogi Pengharapan: Menghayati Kembali Pedagogi Kaum Tertindas (Yogyakarta: Kanisius, 2001).

12 Paulo Freire, Politik Pendidikan: Kebudayaan, Kekuasaan Dan Pembebasan (Yogyakarta: Pustaka Pelajar, 2007). 
Dalam conscientizacao, hidup secara dialogis dengan kenyataan hidup ialah jalan keluar terbaik terhadap penindasan yang datang dari luar diri kita. Meminjam konsep dialektika roh dari Hegel, Freire percaya bahwa dialog antar subjek mampu mengantarkan pihak-pihak yang berlawanan arus untuk menyudahi pertikaian yang terjadi. Meski demikian, Freire tidak memandang bahwa puncak dialektika ialah roh yang menyadari dirinya sendiri sebagai ialah roh absolut sebab perubahan mesti dirasakan saat ini dan di sini. Artinya bentuk nyata dari dialektika ada di dalam dunia yang sedang kita hidupi, puncak dari kesadaran kritis adalah praksis pembebasan. Menurut Freire, refleksi dan aksi tidak bisa dilepaspisahkan. Freire menulis dengantegas 'di dalam kata kita menemukan dua dimensi; refleksi dan aksi. ${ }^{13}$ Keduanya mesti menjadibagian yang hidup dalam subjek yang kritis.

Freire kemudian membagi 3 jenis kesadaran yang ia sebut kesadaran magis, kesadaran naif, dan kesadaran kritis. Kesadaran magis ialah kesadaran terendah dalam diri manusia. Pada kesadaran magis, orang menggantungkan nasib atau arah pikiran dan tindakannya pada kehendak magis dari luar dirinya, dalam hal ini teologi juga termasuk kesadaran magis. Kesadaran kedua yaitu naif tidak jauh berbeda dengan kesadaran magis hanya saja pada kesadaran naif, orang menggantukan arah berpikir dan tindakannya kepada kehendak manusia. Sedang kesadaran kritis, ialah kesadaran yang memunculkan sikap otonom dan subjektifitas seorang individu. ${ }^{14}$ Dalam kesadaran kritis, orang tidak lagi menggantungkan arah berpikir dan bertindak dari subjek di luar dirinya melainkan mengandalkan dirinya sebagai penentu keputusan diri secara subjektif. Singkatnya, pada kesadaran magis dan naif, individu dijadikan sebagai objek dari individu lain di luar dirinya sedangkan dalam kesadaran kritis individu menjadi subjek atas dirinya sendiri karena sikap kritis.

Bagian yang tak kalah penting dalam berdialog, dalam kata dan aksi, dilakukan dengan sikap hati yang tulus, iklas dan penuh cinta kasih. Meminjam ide nekropolis (sikap sadistik) dari Erick Fromm, Freire percaya bahwa kesadaran penindasan lahir dari keadaan hati yang tidak mampu mencintai. Freire menulis, bukan orang yang tidak dicintai yang tidak melahirkan sikap senang itu, tetapi mereka yang tidak dapat mencintai sesamanya dan hanya mencintai diri sendiri. ${ }^{15}$ Oleh karena itu, sebuah dialog atau perjuangan bersama kaum tertindas harus ditopang oleh hati dan pikiran yang bersih dan jujur. Mesti ditopang oleh keinginan untuk berjuang menghapus kekerasan dan penindasan sampai ke akar-akarnya. Dengan didasarkan pada cinta kasih, sebuah perjuangan akan bergerak untuk mengupayakan agar para kaum tertindas terbentuk

\footnotetext{
${ }^{13}$ Freire, Pendidikan Kaum Tertindas.

${ }^{14}$ Ibid.

${ }^{15}$ Ibid.
} 
menuju sebuah keadaan yang manusiawi. ${ }^{16}$ Ide cinta kasih ini adalah perekat solidaritas kaum penindas bersamaan dengan sikap kritis.

\section{Antonia Harder: Pembebasan Pada Tubuh yang Tertindas}

Ada pandangan yang menemukan narasi penindasan baru dalam karya Paulo Freire, Pendidikan sebagai Praktik Pembebasan. Salah satu tanggapan datang dari bell hooks, seorang feminis berkulit hitam, yang mengatakan bahwa pembacaan Freire terhadap penderitaan masih bersifat satu arah dan bias gender. bell hooks mengklarifikasi langsung ke Freire dan menulis,

In a discussion with Freire on this issue, he supported wholeheartedly this'criticism of his work and urged me to share this with readers.) The sexist language in these translated texts does not prevent feminist activists from identifying with or learning from the message content. It diminishes without negating the value of the works. It also does support and perpetuate sexist oppression. ${ }^{17}$

Salah satu pemikir yang dipengaruhi oleh Freire adalah Antonia Harder, seorang pakar pendidikan yang berkonsentrasi pada ide relasi tubuh dan pengetahuan dalam filsafat pendidikan Freire. Dengan meminjam ide Freire mengenai relasi subjek-objek dalam hal mendidik, Harder melihat bahwa tindakan dehumanisasi kaum penindas secara langsung juga menciptakan objektifikasi pada tubuh. Harder menemukan bahwa ada kaitan langsung antara pengetahuan masyarakat tentang tubuh dengan cara pandang seorang subjek didik. Salah satu bentuk nyata adalah pola pemahaman masyarakat yang dibentuk pada jenis kekerasaan saat ini seperti seksisme, rasisme, dan lain sebagainya. ${ }^{18}$ Oleh karena itu, pendidikan mestinya masuk pada percakapan mengenai kehidupan subjek didik secara utuh, atau dalam hal ini, membaca pengalaman pada penindasan atas realitas keberagaman kebertubuhan para subjek didik. Analisa ini dipakai Harder untuk membaca isu rasisme dan penindasan kapitalisme pada konteks Harder di dunia pendidikan Amerika.

Menurut Harder, pola penindasan pada tubuh adalah sebuah ajaran lama yang diulang pada masa ini. Ajaran pemisahan itu juga datang dari Gereja dan filsafat Barat. Dalam ajaran Kristiani, ajaran tubuh dan jiwa telah menciptakan ajaran mengenai kemurnian (puritan). ${ }^{19}$ Pada model pendidikan saat ini, lemahnya respons pendidikan untuk melihat tubuh diprakarsai oleh bangunan pendidikan yang cenderung menempatkan ranah kognitif (kecerdasan intelektual) sebagai ikon pendidikan. ${ }^{20}$ Oleh karena itu, ide-ide abstrak menjadi perhatian utama dalam model pendidikan. Maka dari itu tubuh sebagai benda material menjadi bagian dari manusia yang tidak dianggap

${ }^{16}$ Ibid.

${ }^{17}$ Bell Hooks, Feminist Theory: From Margins to Center (New York: Routledge, 2015).

18 Antonia Harder, "Freire and Body," in Encyclopedia of Educational Philosophy and Theory, ed. Michael A. Peters (Singapore: Springer Science Business Media, 2017), 2453.

19 Antonia Harder, "Decolonizing the Flesh: The Body, Pedagogy, and Inequality," in Postcolonial Challenges in Education, ed. Roland Sintos Coloma (Bern Swiss: Peter Lang Publishing, 2009), 382.

20 Ibid. 
sebagai kualitas pendidikan dari subjek didik. Dalam ajaran yang lebih kekinian, ekonomi kapitalisme telah mengkonkretkan tubuh sebagai materi yang dapat dijadikan objek pelipatan keuntungan seperti yang terjadi dalam model ekonomi saat ini. ${ }^{21}$

Lebih lanjut, penting untuk membangun sebuah paradigma baru mengenai relasi kebertubuhan yang mampu membebaskan dan memungkinkan subjek berelasi dengan dunia secara kritis dan melibatkan semua eksistensi manusia dalam kebertubuhannya (flesh). ${ }^{22}$ Demi mencapai tujuannya, Harder banyak beranjang pada ide pedagogy of heart dari Freire. Harder menekankan bahwa seorang pendidik perlu memiliki rasa peka (sensibility) sehingga mampu melihat kondisi subjek didik dalam memahami tubuh mereka sendiri. ${ }^{23}$ Masuk dalam pandangan tentang tubuh subjek didik artinya kita masuk ke dalam cara pandang subjek didik tentang pengalaman kebertubuhannya sendiri dan cara subjek didik melihat dunia dalam pengalaman itu. Sensibilitas membantu pendidikan dan subjek didik mencapai sebuah pendidikan yang menyentuh tubuh dan pengalaman eksistensial semacam ini disebut Harder sebagai pedagogy of the flesh.

Untuk memulai sebuah pendidikan kritis, pendidikan mesti dibangun dengan mengizinkan setiap murid untuk berpandangan dari persepsi mereka masing-masing. Setiap murid mesti dilihat sebagai seorang manusia yang utuh (whole person) sebab pendidikan yang tidak mengajak subjek didik hadir sebagai manusia tidak melaksanakan pendidikan sama sekali. Pendidik tidak lagi mengajar untuk murid melainkan belajar bersama murid. ${ }^{24}$ Di tahap ini pendidikan yang membebaskan dimulai dengan melibatkan subjek yang menubuh (embodied being) dan bukan lagi subjek yang dikotak-kotakkan dalam struktur tertentu yang bersifat mengistimewakan tubuh pihak tertentu. Pendidikan pun dijalankan melalui refleksi yang melibatkan narasi penderitaan dan perjuangan subjek didik,

Radical reflections born of emancipatory vigilance and grounded in the interdependent dialectics of the body and difference are powerful safeguards gainst curricular epistemicides and political subjugation, in that these transgressive reflections can trigger dissent, breakdowns, and disruptions of hegemonic privilege and exclusion that are fueled by the tyranny of the body. ${ }^{25}$

Dengan membuka ruang bagi pola pendidikan yang melibatkan partisipasi aktif subjek didik, relasi tubuh para subjek didik dapat menjadi sebuah pola pendidikan yang memungkinkan lahirnya resistensi. ${ }^{26}$ Ranah pendidikan menjadi sebuah pola kesadaran

${ }^{21}$ Antonia Harder, "Paulo Freire and The Continuing Struggle Of to Decolonize Education," in Paulo Freire: The Global Legacy, ed. Tina Besley and Michael Peters (New York: Peter Lang Publishing, 2015 ), 604.

${ }^{22}$ Harder, "Decolonizing the Flesh: The Body, Pedagogy, and Inequality."

${ }^{23}$ Antonia Harder, "Preface: Reflections On Pedagogy in The Flesh," in Pedagogies in The Flesh: Case Studies On The Embodiements Social Cultural Differences, ed. and Tyson E. Lewis Sarah Travis, AMelia M Kraehe, Emili J Hood (Bern Swiss: Palgrave Macmillan, 2018), 220.

${ }^{24}$ Harder, "Decolonizing the Flesh: The Body, Pedagogy, and Inequality."

${ }^{25}$ Harder, "Preface: Reflections On Pedagogy in The Flesh."

${ }^{26}$ Harder, "Decolonizing the Flesh: The Body, Pedagogy, and Inequality." 
bersama untuk membangun hidup dalam kesadaran yang asali. Lebih daripada itu, mengutip fenomenologi tubuh Ponty, Harder menandaskan bahwa subjek didik dan murid dapat memahami mengenai pengalaman tubuh dan memahami bagaimana upaya seorang subjek didik memaknai kembali penderitaan (meaning the pain). ${ }^{27}$ Kesadaran akan pemaknaan ketertindasan pada tubuh menjadi locus pembelajaran sekaligus dasar dari pembebasan akan tubuh yang tertindas. Secara khusus, Harder mendialogkan sendiri proses keluar dari "memori trauma" masa kecilnya lewat memaknai kembali tubuhnya yang mengalami kekerasan seksual dalam refleksinya berjudul "Childhood Trauma and The Struggle for Liberation. ${ }^{28}$ Pendasaran yang dilakukan Harder mengajak pembacanya pada model pendidikan yang berangkat dari narasi tubuh sang korban yang berperan penting dalam penelitian mengenai politik tubuh dan pendidikan.

\section{Penderitaan Ganda Para Korban Perdagangan Manusia}

Mery Kolimon mencatat bahwa terdapat 3 faktor utama hadirnya tindak pidana perdagangan orang (TPPO) di NTT. Tiga alasantersebut antara lain, (1) kemiskinan dan pengangguran, (2) patriarkhi yang diganaskan oleh faktor budaya, dan (3) warisan kolonial dalam rupa dorongan kuat dari orang Nusa Tenggara Timur untuk hidup berkelimpahan harta yang merupakan ciri khas masyarakat modern. ${ }^{29}$ Di samping faktor itu, Dominggus Elcid Li secara terang-terangan menyimpulkan bahwa lemahnya proses peradilan hukum di NTT sebagai salah satu dalangnya. ${ }^{30}$ Dalam tulisannya "Perdagangan Orang, Krisis Rule of Law, dan bangkitnya Gereja," ElCid Li menunjukan bahwa kurangnya tenaga ahli dalam sistem peradilan di NTT serta korupnya sistem administrasi di NTT membuat tindak pidana perdagangan orang (TPPO) di NTT. ${ }^{31}$

Mewabahnya TPPO di NTT menghadirkan sebuah kejadian menyakitkan yaitu kekerasan dan fakta berpulangnya para korban dalam keadaan tidak bernyawa. Pada tahun 2020-2021 yang masih berlangsung ini tercatat 50 jenazah korban perdagangan manusia yang dipulangkan ke NTT. ${ }^{32}$ Para korban yang berhasil pulang dalam keadaan hidup,harus menghadapi bentuk penderitaan baru. Lia Wetangterah, seorang aktivis dari Jaringan Perempuan Indonesia Timur (JPIT) mencatat terdapat beberapa macam kekerasan yang dialami oleh para korban sebagai berikut,

\footnotetext{
${ }^{27}$ Harder, "Preface: Reflections On Pedagogy in The Flesh."

${ }^{28}$ Antonia Harder, "Childhood Trauma and the Struggle for Liberation," TruthOut, last modified 2015, http://www.truth-out.org/speakout/item/31654-childhood-trauma-and-the-struggle-for-liberation.

${ }^{29}$ Mery Kolimon, "Kerentanan Dan Luka, Perlawanan Dan Penyembuhan: Refleksi Teologis Tentang Perdagangan Orang Di Wilayah Pelayanan Gereja Masehi Injili Di Timor (GMIT)," in Menolak Diam: Gerja Melawan Perdagangan Orang, ed. Rappan Paledung Mery Kolimon, Hans, A. Harmakaputra, Toar Hutagalung (Jakarta: BPK Gunung Mulia, 2018), xviii+266.

${ }^{30}$ Domingggus ElCid Li, "Perdagangan Orang, Krisis Rule Of Law, Dan Bangkitnya Gereja," in Menolak Diam: Gereja Melawan Perdagangan Orang, ed. Rappan Paledung Mery Kolimon, Hans Harmakaputra, Toar Hutagalung (Jakarta: BPK Gunung Mulia, 2018), xvii+266.

${ }^{31}$ Ibid.

${ }^{32}$ Emmy Sahertian, Orang Muda \& TPPO Di NTT (Kupang, 2020).
} 
(1) Kekerasan fisik; dipukul dengan benda tajam dan tumpul, ditendang, ditampar, kerja melebihi waktu yang seharusnya, dijambak, disetrum, bekerja lebih dari dua tempat kerja. (2) kekerasan psikis: diculik, disekap, dicaci-maki, dihina, dimarahi, diancam, pemaksaan, dilarang menghubungi keluarga, dilarang beribadah, rambut digunduli (perempuan), dipaksa makan makanan busuk, penelantaran, sanitasi yang buruk, penelantaran jasa. (3) Kekerasan seksual; pemerkosaan, pelecehan seksual, diberi pil antihaid. (4) Kekerasan ekonomi: gaji yang tidak dibayar, tidak dapat asuransi, penipuan (kontrak kerja, budaya, gaji, tidak diberi makan, ruangan kerja yang tidak sehat, pungutan liar, tidak ada pelatihan kerja, upah yang diterima tidak sesuai kontrak kerja dan UMR, kelaparan, tidak ada rumah sehingga tinggal di hutan). ${ }^{33}$

Lebih lanjut, mereka yang pulang mesti memikul trauma karena rasa bersalah yang mereka lahirkan bagi diri sendiri dan stigma yang masyarakat sematkan para mereka. Dalam percakapan penulis dengan Yuli Benu, salah satu aktivis TPPO di NTT dari LSM Jaringan Perempuan Indonesia Timur, Yuli mengatakan bahwa masih banyak orang NTT yang antipati terhadap kasus ini. Ada pihak-pihak tertentu yang berkata "Ko itu dong pung salah na, sapa suru ko pi kerja di sana (itu salah mereka, mengapa harus pergi kerja sebagai buruh migran). ${ }^{34}$ Ada juga tanggapan lain yang berbunyi, "Eh ko itu bukan beta pu urusan aang" (ah, itu bukan urusan saya). ${ }^{35}$

Seorang aktivis TPPO di NTT lain bernama Elina Otu mengafirmasi pernyataan Yuli Benu di atas. Menurut Elina, stigma bersalah dari masyarakat itu menegaskan bahwa stigma buruk yang diberikan masyarakat kepada para korban lahir karena kegagalan masyarakat melihat perdagangan manusia sebagai migrasi terpaksa. ${ }^{36}$ Tidak hanya berhenti sampai di situ, tindakan untuk menyalahkan diri itu muncul dari mulut-mulut para korban. Salah satunya ialah Maria, seorang mantan pembantu rumah tangga di Riau yang harus kehilangan kakinya karena amputasi. Yanti Giri, seorang aktivis TPPO di NTT yang mewawancarai Maria menulis,

Dalam upaya memahami apa yang dialaminya, Maria sampai pada kesimpulan bahwa dosanyalah yang menyebabkan ia kehilangan anggota tubuhnya. Ia merasa berdosa karena melalaikan tugasnya sebagai seorang pengajar sekolah minggu dan lebih memilih keluar dari kampung bekerja. Keyakinan inilah yang akhirnya membuat Maria belajar menerima kenyataan yang ada. Maria tidak sendiri. Ada banyak Maria di luar sana, yang berbekal pengajaran Kristen yang pernah dialaminya, menerima begitu saja setiap

${ }^{33}$ Lia Wetangterah, "Kerentanan Masyarakat Nusa Tenggara Timur (NTT) Menjadi Korban Perdagangan Orang Dengan Modus Pekerja Migran Di Indonesia," in Menolak Diam: Gereja Melawan Perdagangan Orang, ed. Rappan Paledung Mery Kolimon, Hans Harmakaputra, Toar Hutagalung (Jakarta: BPK Gunung Mulia, 2018), $\mathrm{xviii}+266$

${ }^{34}$ Yuli Benu, Interview (Kupang, 2020).

${ }^{35}$ Ibid.

${ }^{36}$ Elina Otu, "Jalan Panjang Menuju Penegakan Keadilan Dan Penyembuhan Trauma," in Tuhan Tak Berdagang: Perdagangan Orang, Trauma, Dan Teologi Di Nusa Tenggara Timur, ed. Karen Campbell-Nelson (Jakarta: BPK Gunung Mulia, 2020), xxiv+245. 
ketidakadilan yang ia alami karena merasa bahwa ia memang pantas menerima itu sebab sudah bersalah terhadap Tuhan. ${ }^{37}$

Seorang buruh migran lain yang kembali menyalahkan dirinya adalah Nori. Nori adalah seorang remaja berumur 14 tahun yang harus menerima kekerasan seksual di usia belianya. Nori berkata, "Nori rasa itu (masalah) dari Tuhan. Selama Nori kerja sibuk, sonde ${ }^{38}$ pernah pi (pergi) (ke) Gereja, sonde dekat dengan Tuhan. Sampai masalah, Nori ingat Tuhan, Nori rasa su (sudah) jauh. Ini Tuhan kasi (memberikan) pelajaran supaya jangan jauh dari Tuhan. ${ }^{39 "}$ Pernyataan Nori mengandung sebuah pesan yang kuat bahwa ia percaya Tuhan tidak meninggalkan dia dalam keadaan pelik yang ia jalani. Kendati demikian, tersirat pesan bahwa Nori merasa kesalahan itu adalah peringatan keras pada dirinya untuk tetap memperhatikan imannya. Pernyataan Nori itu ditanggapi oleh Mery Kolimon dalam berbentuk sebuah refleksi sebagai berikut,

Nori menyalahkan diri bahwa eksploitasi seksual yang dia alami karena dia tidak rajin ke gereja. Hal ini dapat saja terkait pandangan budaya lokal bahwa suatu krisis terjadi karena kesalahan yang dilakukan, entah oleh mereka yang mengalami krisis atau anggota keluarganya. Dalam tradisi naketi di Timor, misalnya, suatu upaya untuk mengalami pemulihan adalah dengan pengakuan "dosa." Korban merasa bebannya menjadi lebih ringan dan ada harapan untuk pemulihan setelah mengakui dosa dan kelemahannya. Hal ini memiliki sisi baik untuk otokritik agar orang tersebut mampu belajar dari kelemahan masa lalu. Namun, ada juga dampak negatif bahwa korban tidak kritis terhadap struktur sosial, ekonomi, dan politik yang menjebaknya masuk ke dalam lingkaran kejahatan manusia. ${ }^{40}$

\section{Analisa Kritis Terhadap Narasi Bersalah Para Korban Perdagangan Manusia}

Dalam melihat wacana rasa bersalah yang muncul dalam diri para korban, penulis menganalisis bahwasa narasi rasa bersalah yang muncul dalam persoalan PMNTT berangkat dari matinya daya kritis masyarakat NTT dan warga Gereja Masehi Injili di Timor (GMIT) dalam melihat lapisan persoalan secara luas. Tanda dari ketidakhadiran kesadaran kritis (istilah Freire) itu ditunjukan lewat pola blaming the victims. ${ }^{41}$ Narasi menyalahkan para korban lahir dari kegagalan masyarakat untuk melihat 'pelaku sebenarnya' dari kasus ini dan faktor-faktor penyebab yang menjadikan masyarakat NTT menjadi 'korban' tetapi malah menjadikan korban sebagai pelaku. Sikap menyalahkan para korban yang datang dari masyarakat NTT secara umum dan warga GMIT sendiri

37 Yanti Giri, “Amputasi Dan Trauma," in Tuhan Tak Berdagang: Perdagangan Orang, Trauma, Dan Teologi Di Nusa Tenggara Timur, ed. Karen Campbell-Nelson (Jakarta: BPK Gunung Mulia, 2020), xxiv+245.

${ }^{38}$ Sonde adalah bahasa kupang yang diserap dari kosa kata Belanda kuno yang berarti "tidak" dalam bahasa Indonesia.

${ }^{39}$ Adi Amtara, “Ajakan Berlibur Berujung Kekerasan Seksual,” in Tuhan Tak Berdagang: Perdagangan Orang, Trauma, Dan Teologi Di Nusa Tenggara Timur, ed. Karen Campbell-Nelson (Jakarta: BPK Gunung Mulia, 2020), xxiv+245.

${ }^{40}$ Mery Kolimon, "Misi Gereja Sebagai Pendampingan," in Tuhan Tak Berdagang: Perdagangan Orang, Trauma, Dan Teologi Di Nusa Tenggara Timur, ed. Karen Campbell-Nelson (Jakarta: BPK Gunung Mulia, 2020), $\mathrm{xxiv}+245$

${ }^{41}$ \& Mansour Fakih Roem Topatimasang, Toto Rahardjo, Pendidikan Populer Membangun Kesadaran Kritis (Yogyakarta: InsistPress, 2001). 
secara umum adalah tanda matinya solidaritas kemanusiaan dan nalar kritis (konsientisasi).

Absennya nalar kritis dari pihak yang menyalahkan korban, termasuk korban itu sendiri, adalah tanda dari pola pendidikan gaya bank yang hidup dalam komunitas masyarakat menyalahkan. Pada pihak GMIT, pendidikan gaya bank itu terbukti ada oleh karena wacana teologi penjajahan yang masih hadir dalam narasi korban. Pola pendidikan bank tersebut dapat dilihat dari absennya respons kritis Nori dan Maria pada sebuah kasus yang menimpa dirinya tersebut. Absennya sikap kritis GMIT dalam cakupan ajarannya memunculkan sebuah ciri utama dari ketiadaan pendidikan gaya bank membuat sang pelayanan gereja hanya meneruskan prinsip ajaran yang sudah diajarkan pada Maria dan Nori. Alhasil, Maria dan Nori tidak melihat faktor kedua maupun ketiga dari persoalan yang menimpa dirinya. Maria dan Nori memilih membenamkan diri dalam apa yang disebut Freire sebagai kesadaran magis, yakni kesadaran bahwa kesalahan atau beban yang menimpa dirinya datang dari dunia supranatural di luar kuasa dirinya atau dalam kasus Maria dan Nori datang dari Allah orang Kristen. ${ }^{42}$

Narasi gaya bank yang datang dari pengulangan warisan kolonialisme tidak hanya hadir pada diri korban TPPO di NTT tetapi juga muncul dalam narasi mempersalahkan korban yang datang dari pihak luas (masyarakat NTT yang mempersalahkan korban). Pasalnya, narasi mempersalahkan korban berangkat dari sebuah pemahaman bahwa satu-satunya kesalahan terletak pada diri korban semata dan bukan diarahkan kepada lingkaran sistem yang menjebak korban. Artinya pola penilaian yang hadir tidak melibatkan proses refleksi kritis atas kasus yang terjadi dan hanya berpusat semata pada pengambil tindakan alias para korban TPPO di NTT. Dengan kata lain, cengkraman kolonial yang terbenam lama dalam corak kebudayaan masyarakat dan ajaran GMIT telah menciptakan penindas-penindas baru dalam pribadi-pribadi yang 'menamai' para korban TPPO di NTT sebagai 'pelaku' yang perlu bertanggungjawab atas kasus yang menimpa mereka.

Dalam pola relasi salah-menyalahkan yang bercokol dalam kebudayaan masyarakat NTT semacam ini, masyarakat NTT dan gereja secara khusus perlu memikirkan sebuah struktur pendidikan baru yang bersifat membebaskan. Gereja bertanggungjawab penuh untuk merombak pola ajarannya yang diteruskan saja pada masa sekarang tanpa sikap kritis untuk memperhadapkan umatnya pada masalah TPPO di NTT secara komperhennsif. Oleh Mariska Lauterboom, upaya untuk keluar dari pikiran

42 Dalam prespektif pribadi penulis yang juga adalah seorang Kristen, kesadaran magis mengantarkan Maria dan Nori berdosa yang amat mendalam. Pertanyaannya kritis dalam membaca kasus yang menimpa mereka berdua, siapakah yang sepantasnya menanggung dosa itu? 
kolonial semacam ini adalah bagian dari panggilan untuk melakukan dekolonisasi pendidikan agama Kristen. ${ }^{43}$

Kebutuhan dekolonisasi pendidikan dalam ajaran pendidikan GMIT amat dibutuhkan melihat kondisi saat ini di mana GMIT harus bertarung dengan narasi penindasan yang lahir dari virus kolonialisme dan himpitan kapitalisme dalam bentuk TPPO di NTT. Himpitan dua paham tadi memaksa GMIT untuk bekerja melawan bentuk, dalam istilah penulis, penindasan internal dan eksternal. Penindasan internal datang dari tubuh GMIT sendiri dalam rupa kesadaran naif yang masih menjangkiti tubuh GMIT dan implikasi pengetahuan gaya bank yang datang dari masyarakat NTT yang bersikap sok tahu dan ikut memperparah keadaan para korban dengan istilah-istilah menindas. Maka dari itu, keberadaan GMIT yang sedang ikut campur dalam urusan TPPO di NTT sebenarnya sedang menempatkan posisi yang rentan ibarat pepatah "memakan buah simalakama."

Lebih lanjut, fakta bahwa siapa pun bisa menjadi pelaku perdagangan manusia menuntut sebuah gerakan transformasi misi GMIT ke dimensi pendidikan agar ajaran GMIT mampu hidup dalam tindakan umat. Namun sejauh ini, dimensi pendidikan belum mendapat perhatian besar dari GMIT. ${ }^{44}$ Tema utama dari basis gerakan GMIT untuk melawan perdagangan manusia, perlawanan tersebut dinamakan 'misi perlawanan. Misi Gereja melawan perdagangan orang kemudian menjadi landasan bergerak bersama komunitas gereja dan masyarakat secara luas untuk bersatu melawan tindak pidana perdagangan orang di Nusa Tenggara Timur (TPPO di NTT). Kolimon menambahkan, misi Gereja bersama korban/penyintas menjadi praksis perlawanan/resistensi untuk melawan teologi kepasrahan yang membenamkan masyarakat NTT dalam keadaan pasif. ${ }^{45}$ Misi Gereja diarahkan langsung pada relasi kekuasaan yang menjadi sumber penderitaan korban/penyintas perdagangan manusia. Itu mesti didorong untuk memungkinkan sebuah transformasi, tempat para korban merekonstruksi identitas diri mereka dari korban menjadi penyintas, dan dari penyintas menjadi agen misi. ${ }^{46}$ Melalui metafora "orang samaria yang murah hati, Kolimon menegaskan,

Tugas kita bersama dengan berbagai pemangku kepentingan di negeri ini bukan hanya menyiapkan, di negeri ini, akses bagi pelayan rumah sakit dan penginapan untuk para korban yang dirampok, seperti cerita Orang Samaria yang Murah Hati." Tugas kita adalah untuk memastikan agar jangan lagi ada perampok dan orang yang dirampok "dalam perjalanan dari Yerusalem ke Yerikho" itu (Lukas 10: 25-37). Tanggung jawab kita

\footnotetext{
${ }^{43}$ Mariska Lauterboom, "Dekolonisasi Pendidikan Agama Kristen Di Indonesia,” Indonesian Journal of Theology 7/1, no. Edisi Spesial Pendidikan Kristiani di Indonesia (2019): 88-110.

${ }^{44}$ Lihat penjelasan mengenai penelitian GMIT sejauh ini dalam Menolak Diam: Gereja Melawan Perdagangan Orang terbitan BPK Gunung Mulia pada tahun 2018 dan "Tuhan Tak Berdagang: Perdagangan Orang, Trauma, dan Teologi di Nusa Tenggara Timur” terbitan BPK Gunung Mulia pada tahun 2020.

${ }^{45}$ Mery Kolimon, "Gereja Melawan Ketidakadilan: Rekonstruksi Teologi Misi Sebagai Perlawanan," in Annual Meeting Asosiai Teologi Di Indonesia Ke-5 Di Malang, Jawa Timur (Malang, 2017).

46 Kolimon, "Kerentanan Dan Luka, Perlawanan Dan Penyembuhan: Refleksi Teologis Tentang Perdagangan Orang Di Wilayah Pelayanan Gereja Masehi Injili Di Timor (GMIT).”
} 
bukan hanya untuk bersama korban, melainkan juga memastikan bersama sistem kehidupan bangsa: hukum, ekonomi, politik, budaya, yang mencegah jatuhnya korban. ${ }^{47}$

Untuk memenuhi tujuan itu, paradigma 'misi perlawanan' sebenarnya adalah pintu masuk menuju dimensi pendidikan jemaat. Konsepsi misi perlawanan, dalam istilah Freire, adalah sebuah commonword untuk memperhadapkan umat GMIT pada persoalan Bersama, yakni perdagangan manusia. Misi perlawanan 'menamai' konteks yang ada untuk melawan perdagangan manusia sebagai sikap iman. Serta keimanan itu menjadi nyata dalam cerita Orang Samaria yang Baik Hati. Secara lebih mendalam, kita dapat melihat teori pedagogi Paulo Freire dan Antony Harder bertemu dengan konteks GMIT. Pertama, dalam misi perlawanan adalah dimensi kesadaran kritis sebab dalam paradigma misi perlawanan, korban perdagangan manusia tidak bisa dinyatakan sebagai pelaku dari kejahatan yang mereka alami. Dari sudut pandang kesadaran naif, mungkin bisa mereka bersalah secara pribadi antara mereka dan kenyataan yang mereka alami. Itulah mengapa yang terpancar dari pernyataan Maria dan Nori sekaligus jawaban dari mengapa mereka gagal melihat permainan mafia di balik kasus yang menimpa mereka berdua. Kendati demikian, dalam pemahaman yang lebih kritis sekaligus mendalam, para pelaku sebenarnya ialah para oknum dari tindakan kejahatan besar perdagangan manusia. Maka, para korban tidak bisa dikenakan tuduhan bersalah (blaming victim) atas kejahatan yang mereka alami. Para korban hanyalah orang yang sedang ingin pergi bekerja. Tidak lebih dan tidak kurang, persis seperti orang yang sedang ingin melakukan perjalanan seperti pada cerita orang Samaria.

Kedua, melalui misi perlawanan, warga Gereja dimungkinkan untuk terlibat aktif melalui setiap keberadaan ekesistensialis mereka masing-masing. Oleh karena itu, sikap iman bisa dilakukan dengan beranjak dari konteks kehidupan warga GMIT. Perlawanan terhadap perdagangan manusia dilakukan dengan peningkatan mutu tindakan atau refleksi warga GMIT pada ranah pekerjaan dan pelayanan yang mereka lakukan. Hal ini dilakukan karena luasnya persoalan seperti ekonomi dan sosial yang menyebabkan terjadinya perdagangan manusia dan cara melawnanya ialah dengan mengandalkan efektifitas ekonomi dan sosial. Dengan demikian, warga GMIT, dalam perumpamaan Samaria, telah hadir sebagai orang Samaria yang murah hati sekaligus menjadi pemilik penginapan dengan latar belakang mereka masing-masing maka setiap tindakan reflektif yang warga Gereja lakukan saat ini demi melawan perdagangan manusia adalah sikap iman.

Paham misi perlawanan memungkinkan pendekatan perlawanan secara multi keilmuan dan multivokal terhadap perdagangan manusia. Seluruh warga GMIT bisa bertindak menjadi sahabat bagi para korban perdagangan manusia apabila mendialogkan keterampilan pribadi secara langsung pada kasus perdagangan manusia. Oleh karena itu,

${ }^{47}$ Ibid. 
penulis kemudian membagi 2 model perlawanan terhadap TPPO di NTT ke dalam 2 bagian; perlawanan langsung dan perlawanan tidak langsung. Perlawanan langsung ialah perlawanan yang dilaksanakan oleh GMIT bersama berbagai LSM yang menopang mereka terhadap para pelaku. GMIT menjadikan TPPO di NTT sebagai tema utama dan mengarahkan berbagai sumber daya Gereja untuk agenda perlawanan. Yang kedua, perlawanan tidak langsung ialah perlawanan yang dikerjakan GMIT dengan memperluas cakupan 'tema' misi perlawanan. Artinya terdapat alternatif tema perlawanan seperti tema kebudayaan dan ekonomi kemasyarakatan. Contoh pelawanan model kedua akan penulis jelaskan secara konkrit dalam uraian mengenai Lakoat.Kujawas.

Ketika menyebut Lakoat.Kujawas penulis sedang tidak melakukan tindakan asal pilih. Pemilihan Lakoat.Kujawas yang diprakarasi oleh Dicky Senda didorong juga olehsebuah apresiasi dari seorang aktivis PMNTT Suster Laurentia, kepada Dicky Senda dalam mengangkat ke permukaan isu rendahnya kualitas pendidikan di Desa Taiftob.sebuah desa di Mollo-So'e yang mempunyai pengalaman langsung dengan PMNTT. Melihat pekerjaan mulia yang dilakukan Dicky, Suster Laurentia dalam doanya berkata "Tuhan berikanlah Dicky-Dicky yang lain untuk membangun dan mengembangkan Tanah Timor. ${ }^{48 ”}$

\section{Sekilas Mengenai Lakoat Kujawas ${ }^{49}$}

Lakoat.Kujawas adalah sebuah komunitas wirausaha masyarakat warga yang terletak di desa Taiftop-Kapan, Timor Tengah Selatan. Lakotas Kujawas didirikan oleh seorang pemuda bernama Christian Dicky Senda. Lakoat (biwa) dan Kujawas (jambu biji) ialah dua buah yang akrab dengan kehidupan anak-anak Mollo. Keduanya menggambarkan keceriaan, potensi, dan harapan yang tumbuh dari kampung-kampung di Mollo.

Mulanya, kepulangan Dicky ke Taiftob hanya untuk melakukan riset. Saat itu ia masih bekerja di Kupang sebagai konselor pendidikan. Ternyata banyak yang ia temukan dalam proses riset itu. Dicky melihat bagaimana kampungnya, dan kampung-kampung lain di Timor, ditinggal pergi oleh orang-orang mudanya. Mereka putus sekolah kemudian merantau mencari penghidupan. Ada yang ke luar daerah, bahkan tidak sedikit yang menjadi buruh migran ke Malaysia. Ia juga mendengar banyak dari mereka menjadi korban perdagangan orang atau pulang dalam kondisi terjangkit HIV. Akhirnya, Dicky membulatkan tekad untuk melepas pekerjaannya dan pulang kampung ke Taiftob. Di hatinya, hanya ada satu niat yakni membuat masyarakat Mollo, terutama orang mudanya,

\footnotetext{
${ }^{48}$ Laurentia, "Hancurlah Mimpi-Mimpi," in Tuhan Tak Berdagang: Perdagangan Orang, Trauma, Dan Teologi Di Nusa Tenggara Timur, ed. Karen Campbell-Nelson (Jakarta: BPK Gunung Mulia, 2020), xxiv+245.

${ }^{49}$ Dalam proses penulisan artikel ini, penulis berupaya untuk mengatur waktu bersama Dicky Senda untuk melakukan wawancara langsung. Sayangnya kesempatan itu belum bisa saya dapatkan sampai saat ini. Satusatunya kesempatan adalah dengan ikut serta dalam acara wawancara bersama Lakoat Kujawas yang dilakukan oleh beberapa orang yang berkesempatan mewawancarai Dicky Senda melalui instagramlive. Satu-satunya kesempatan penulis memberikan pertanyaan dan mendapat respons ialah dalam wawancara yang dilakukan oleh @ ssluzf dan @lakoat.kujawas pada tanggal 29 April 2020 pkl 18.00-19.00 WIB (19.00-20.00 WITA)
} 
berdaulat atas alam dan budayanya sendiri. Bersama kawan-kawannya di Taiftob, Dicky mendirikan Lakoat.Kujawas pada 10 Juni $2016 .^{50}$

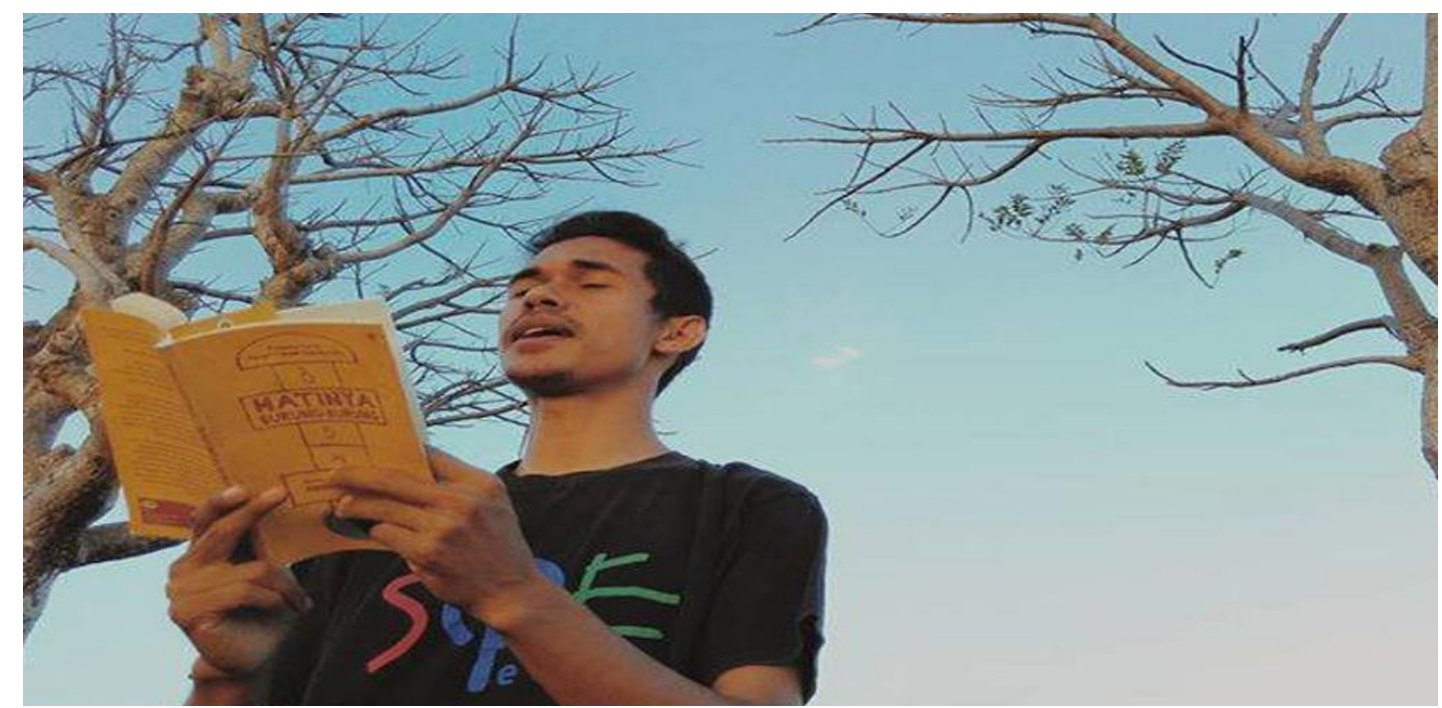

Gambar 1: Christian Dicky Senda || sumber: idwrtires.com

Dalam presentasinya di Wednesday Forum CRCS-ICRS pada 28 November 2018, Dicky memaparkan bahwa Lakoat.Kujawas ingin membuka ruang-ruang kesempatan yang lebih besar terutama bagi perempuan dan anak-anak. Selama 10 tahun Dicky menyelami konsep aktivitasme komunitas di Yogyakarta dan Kupang. Dari sinilah ia belajar dan mulai merencanakan lahirnya Lakoat.Kujawas. Dicky dan kawan-kawannya berusaha memastikan ide-ide dasar mengenai identitas, nilai, dan perkara organisasional memiliki pijakan yang kuat. Lakoat Kujawas akhirnya lahir menyatukan masyarakat yang aktif dalam suatu ekosistem yang kreatif. ${ }^{51}$

Kecintaan Dicky terhadap kebudayaan Mollo terlihat dalam semangatnya menarasikan kembali kebudayaan Mollo yang telah lama ditimbun oleh hegemoni modernitas. Bersama para warga Mollo, Dicky melakukan investigasi terhadap bentuk peninggalan kebudayaan Mollo. Salah satu sumber informasi kebudayaan, tutur Dicky dalam wawancara yang dilakukan melalui bantuan instagramlive, adalah memori kolektif warga. Dicky mengatakan bahwa warga Mollo sebenarnya masih mengingat warisan kebudayaan mereka tertimbun oleh kebudayaan modern. Bersama warga Mollo, Dicky mengadakan pameran dan juga dalam waktu yang akan datang Dicky ingin menciptakan galeri untuk menyimpan hasil-hasil karya warga Mollo agar dapat menjaga kelestarian yang mereka temukan. Mengenai respon terhadap perdagangan orang yang menjadi salah satu faktor berdirinya Lakoat.Kujawas, Dicky mengulas dalam instgramglive bahwa

"Persoalan perdagangan orang adalah sebuah isu global, butuh sebuah gerakan yang besar. Di lakoat.kujawas, kami sendiri terus melakukan wirausaha sosial. Kegiatan itu

\footnotetext{
${ }^{50}$ Koalisiseni, "Budaya Adalah Kekuatan Ekonomi,” Https://Koalisiseni.or.Id, 2020.

${ }^{51}$ Inashabibah, "Lakoat.Kujawas Dan Ikhtiar Revitalisasi Desa Berbasis Adat Di NTT," Https://Crcs.Ugm.Ac.Id (Yogyakarta, 2020).
} 
kami kerjakan dalam bentuk literasi budaya dengan pembuatan puisi agar anak-anak mencintai budaya mereka. Kami juga melakukan ekonomi budaya seperti pembuatan bahan makanan daerah yang terus kami kerjakan. Yang Lakoat.K1ujawas lakukan adalah sebuah upaya yang bersifat kontekstual."

Akhir kata, segala usaha yang dilakukan para relawan Lakoat.Kujawas membuktikan bahwa seni dan budaya terkait erat dengan sandaran ekonomi bagi masyarakat Mollo. Keunikan makanan, hasil karya, dan cerita-cerita sejarah yang telah lama dimiliki warga menyimpan potensi yang tidak kecil. Warga Mollo kini mulai jeli mengamati potensinya dan mampu mengemasnya agar relevan dengan zaman. Selain itu, dengan lebih mengenal budaya mereka sendiri, warga bisa menjadi lebih kuat mempertahankan kehidupan sehingga tidak tergoda jebakan eksploitasi yang dapat merugikan mereka. ${ }^{52}$

\section{Lakoat.kujawas dan Ikhtiar Perlawanan Berbasis Kebudayaan dan Ekonomi}

Keberadaan Lakoat.Kujawas adalah sebentuk perlawanan masyarakat Desa Tiftob di Mollo terhadap kasus perdagangan manusia. Peran tersebut ditunjukkan melalui revitalisasi masyarakat adat di Kapan oleh Dicky Senda dan rekan-rekannya. Lakoat.Kujawas menamakan tema kehidupan lainnya yakni kesejahteraan desa sebagai perjuangan mereka. Revitalisasi dilangsungkan dalam kerangka proses belajar informal untuk membentuk rasa cinta terhadap kebudayaan lokal dan sikap kritis terhadap konteks modern. Bentuk kecintaan pada kebudayaan lokal ditunjukan dengan kegiatan reproduksi kebudayaan dalam bentuk sastra dan panganan budaya yang mereka hasilkan hingga hari ini. Kerja Lakoat.Kujawas menyadarkan masyarakat Taiftob akan pentingnya hidup di desa dan membangun daerah Mollo. Dengan demikian, Lakoat.Kujawas menunjukkan sebuah gerakan masyarakat yang dilandaskan pada kesadaran kritis (Freire) sekaligus kepedulian terhadap narasi tubuh para korban TPPO di NTT. Peran penting Lakoat.Kujawas ialah Perlawanan langsung Lakoat.Kujawas menjadikan menunjukan sebuah bentuk kesadaran subjek dalam sebuah komunitas pendidikan dengan melandaskan tindakan mereka pada kekuatan budaya dan ekonomi kemasyarakatan.

Lakoat.Kujawas hadir sebagai salah satu aktor untuk, dengan bercermin pada kisah Orang Samaria, mencegah adanya korban dan dan perampok baru dalam kasus perdagangan manusia di Nusa Tenggara Timur. Oleh karena itu, apa yang dilakukan Lakoat.Kujawas menunjukkan bahwa para korban bukanlah pelaku atas tindakan mereka sendiri. Juga, TPPO di NTT amat bisa dilawan dengan beranjak pada konteks warga GMIT masing-masing asalkan dibangun di atas tindakan kritis. Lakoat.kujawas menghadirkan diri mereka sebagai salah satu agen penyelamat sekaligus menghalau terjadinya

\footnotetext{
${ }^{52}$ Koalisiseni, "Budaya Adalah Kekuatan Ekonomi."
} 
pencurian baru dalam bentuk TPPO dalam bentuk revitalisasi kebudayaan Timor di Mollo.

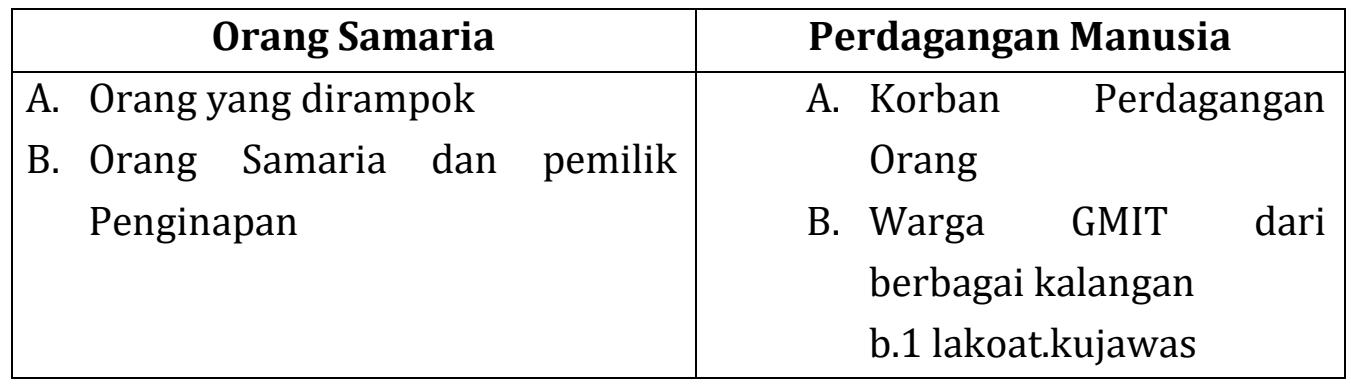

Bagan 1.2

Secara tidak langsung, tanpa direncakanan sebelumnya, Lakoat.Kujawas bergerak bersama dalam tema perlawanan dengan GMIT yakni perlawanan terhadap perdagangan manusia. Lakoat.Kujawas menunjukan bahwa pendidikan kontekstual dapat menjadi peran penting dalam membentuk kesadaran kritis masyarakat dalam menyikapi persoalan perdagangan manusia yang masih terus terjadi sampai saat ini di Nusa Tenggara Timur. Dalam salah satu Seminar, Emmy Sahertian, salah satu aktifis kasus perdagangan manusia dari Sinode GMIT menegaskan bahwa peran Lakoat.Kujawas amat relevan dengan konteks GMIT yang hadir di tengah masyarakat Multikultur seperti Nusa Tenggara Timur. $^{53}$ Oleh karena itu, peran pendidikan kontekstual Lakoat.Kujawas sesungguhnya tidak dapat dipandang sebelah mata oleh GMIT. Lebih jauh, sesungguhnya Lakaot.Kujawas adalah rekan potensial bagi GMIT dalam melawan perdagangan manusia.

\section{Kesimpulan}

Peran pendidikan bagi warga Gereja Masehi Injili di Timor mesti dibangun bersamaan dengan misi perlawanan sebab dalam misi perlawanan terdapat pemahaman iman yang kritis terhadap masalah serta membebaskan bagi tubuh para korban tindak pidana perdagangan orang di NTT. Konstruksi pendidikan tersebut dibangun dengan melibatkan mengaitkan bencana tindak pidana perdagangan orang dengan dimensi kehidupan masyarakat seperti ekonomi, kebudayaan dan lain sebagainya seperti yang dilakukan oleh Lakoat.Kujawas. Dengan belajar dari pengalaman Lakoat.Kujawas, dimensi pendidikan sebagai perlawanan TPPO dalam konteks NTT juga perlu untuk memberikan tempat bagi praktik pembebasan kemanusiaan dan juga kebudayaan serta lingkungan hidup.

${ }^{53}$ Sahertian, Orang Muda \& TPPO Di NTT. 


\section{Referensi}

Amtara, Adi. "Ajakan Berlibur Berujung Kekerasan Seksual." dalam Tuhan Tak Berdagang: Perdagangan Orang, Trauma, Dan Teologi Di Nusa Tenggara Timur, Editor Karen Campbell-Nelson, xxiv+245. Jakarta: BPK Gunung Mulia, 2020.

Daniel Schipani. "Pendidikan Transformasi Sosial." dalam Memetakan Pendidikan Kristani: Pendekatan-Pendekataan Menuju Pembelajaran Jemaat, Editor Jack Seymour, Jakarta: BPK Gunung Mulia, 2018.

Danuwinata, Sastrapratedja. Filsafat Pendidikan Paulo Freire. Jakarta: Sekolah Tinggi FIlsafat Driyarkara, 1984.

Denis Collins. Paulo Freire: Kehidupan, Karya, dan Pemikirannya. Yogyakarta: Pustaka Pelajar, 2011.

Domingggus ElCid Li. "Perdagangan Orang, Krisis Rule Of Law, Dan Bangkitnya Gereja." dalam Menolak Diam: Gereja Melawan Perdagangan Orang, Editor Rappan Paledung Mery Kolimon, Hans Harmakaputra, Toar Hutagalung, xvii+266. Jakarta: BPK Gunung Mulia, 2018.

Freire, Paulo. Pedagogi Hati. Yogyakarta: Kanisius, 2001.

_-_. Pedagogi Pengharapan: Menghayati Kembali Pedagogi Kaum Tertindas. Yogyakarta: Kanisius, 2001.

_-_. Pendidikan Kaum Tertindas. Jakarta: Pustaka LP3ES Indonesia, 2008.

-_- Politik Pendidikan: Kebudayaan, Kekuasaan dan Pembebasan. Yogyakarta: Pustaka Pelajar, 2007.

Giri, Yanti. "Amputasi Dan Trauma." dalam Tuhan Tak Berdagang: Perdagangan Orang, Trauma, dan Teologi Di Nusa Tenggara Timur, Editor Karen Campbell-Nelson, xxiv+245. Jakarta: BPK Gunung Mulia, 2020.

Harder, Antonia. "Childhood Trauma and the Struggle for Liberation." TruthOut. Last modified 2015. http://www.truth-out.org/speakout/item/31654-childhoodtrauma-and-the-struggle-for-liberation.

- - - "Decolonizing the Flesh: The Body, Pedagogy, and Inequality." In Postcolonial Challenges in Education, edited by Roland Sintos Coloma, 382. Bern Swiss: Peter Lang Publishing, 2009.

- - - "Freire and Body." In Encyclopedia of Educational Philosophy and Theory, edited by Michael A. Peters, 2453. Singapore: Springer Science Business Media, 2017.

- - - "Paulo Freire and The Continuing Struggle Of to Decolonize Education." In Paulo Freire: The Global Legacy, edited by Tina Besley and Michael Peters, 604. New York: Peter Lang Publishing, 2015.

."Preface: Reflections On Pedagogy in The Flesh." In Pedagogies in The Flesh: Case Studies On The Embodiements Social Cultural Differences, edited by and Tyson E. Lewis Sarah Travis, AMelia M Kraehe, Emili J Hood, 220. Bern Swiss: Palgrave Macmillan, 2018.

Hooks, Bell. Feminist Theory: From Margins to Center. New York: Routledge, 2015.

Inashabibah. "Lakoat.Kujawas Dan Ikhtiar Revitalisasi Desa Berbasis Adat Di NTT.” Https://Crcs.Ugm.Ac.Id. Yogyakarta, 2020. 
Koalisiseni. "Budaya Adalah Kekuatan Ekonomi.” Https://Koalisiseni.or.Id, 2020.

Kolimon, Mery. "Gereja Melawan Ketidakadilan: Rekonstruksi Teologi Misi Sebagai Perlawanan." In Annual Meeting Asosiai Teologi Di Indonesia Ke-5 Di Malang, Jawa Timur. Malang, 2017.

. "Kerentanan Dan Luka, Perlawanan Dan Penyembuhan: Refleksi Teologis Tentang Perdagangan Orang Di Wilayah Pelayanan Gereja Masehi Injili Di Timor (GMIT)." dalam Menolak Diam: Gerja Melawan Perdagangan Orang, editor Rappan Paledung Mery Kolimon, Hans, A. Harmakaputra, Toar Hutagalung, xviii+266. Jakarta: BPK Gunung Mulia, 2018.

———. "Misi Gereja Sebagai Pendampingan." dalam Tuhan Tak Berdagang: Perdagangan Orang, Trauma, Dan Teologi Di Nusa Tenggara Timur, editor Karen Campbell-Nelson, xxiv+245. Jakarta: BPK Gunung Mulia, 2020.

_-_. "Misi Perlawanan Gereja." dalam Perdagangan Orang, Trauma, Dan Teologi Di Nusa Tenggara Timur, editor Karen Campbell-Nelson, 245. Jakarta: BPK Gunung Mulia, 2020.

Laurentia. "Hancurlah Mimpi-Mimpi." In Tuhan Tak Berdagang: Perdagangan Orang, Trauma, Dan Teologi Di Nusa Tenggara Timur, editor Karen Campbell-Nelson, xxiv+245. Jakarta: BPK Gunung Mulia, 2020.

Lauterboom, Mariska. “Dekolonisasi Pendidikan Agama Kristen Di Indonesia.” Indonesian Journal of Theology 7/1, no. Edisi Spesial Pendidikan Kristiani di Indonesia (2019): 88-110.

Otu, Elina. “Jalan Panjang Menuju Penegakan Keadilan Dan Penyembuhan Trauma.” dalam Tuhan Tak Berdagang: Perdagangan Orang, Trauma, Dan Teologi Di Nusa Tenggara Timur, editor Karen Campbell-Nelson, xxiv+245. Jakarta: BPK Gunung Mulia, 2020.

Roem Topatimasang, Toto Rahardjo, \& Mansour Fakih. Pendidikan Populer Membangun Kesadaran Kritis. Yogyakarta: InsistPress, 2001.

Sahertian, Emmy. Orang Muda \& TPPO Di NTT. Kupang, 2020.

Seymour, Jack. "Pendekatan-Pendekatan Pendidikan Kristiani.” dalam Memetakan Pendidikan Kristani: "Pendekatan-Pendekataan Menuju Pembelajaran Jemaat, editor Jack Seymour, BPK Gunung Mulia, 2018.

Smith, William. A. Conscientizacao: Tujuan Pendidikan Paulo Freire. Yogyakarta: Pustaka Pelajar, 2008.

Wetangterah, Lia. "Kerentanan Masyarakat Nusa Tenggara Timur (NTT) Menjadi Korban Perdagangan Orang Dengan Modus Pekerja Migran Di Indonesia." dalam Menolak Diam: Gereja Melawan Perdagangan Orang, editor Rappan Paledung Mery Kolimon, Hans Harmakaputra, Toar Hutagalung, xviii+266. Jakarta: BPK Gunung Mulia, 2018.

\section{Wawancara:}

Benu, Yuli. Interview. Kupang, 2020. 